\title{
Research on the Impact of Loan Risk Compensation Funds on Regional Technological Innovation Efficiency Based on DEA Model
}

\author{
Meng Wang ${ }^{1,2,3}$ Mu Zhang ${ }^{3}$ \\ ${ }^{1}$ Guizhou Institute for Urban Economics and Development, Guizhou University of Finance \\ and Economics, Guiyang Guizhou 550025, China \\ ${ }^{2}$ Guizhou Institution for Technology Innovation \& Entrepreneurship Investment, Guizhou \\ University of Finance and Economics, Guiyang Guizhou 550025, China \\ ${ }^{3}$ School of Finance, Guizhou University of Finance and Economics, Guiyang Guizhou \\ 550025, China
}

\begin{abstract}
With the rapid economic development of China, regional technological innovation has gradually become the main force of China's scientific and technological innovation. In order to improve the technological innovation efficiency of inputs and outputs, this paper collected the data of 21 prefecture level cities in 2015, the establishment of regional R\&D DEA model based on input-output efficiency evaluation system, to measure the impact of the efficiency of regional innovation. Therefore, it is suggested that the government should appropriately raise the loan risk compensation funds, so as to further promote regional technological innovation and economic development.
\end{abstract}

Keywords

Loan Risk Compensation Funds; Regional Technological Innovation; Regional Technological Innovation Efficiency; DEA Model

\section{基于 DEA 模型的贷款风险补偿资金对区 域技术创新效率的影响研究}

\author{
王蒙 $1,2,3$ 张目 ${ }^{3}$ \\ 1 贵州财经大学贵州城镇经济与发展研究院, 贵阳, 贵州 550025, 中国 \\ 2 贵州财经大学贵州科技创新创业投资研究院, 贵阳, 贵州 550025, 中国 \\ 3 贵州财经大学金融学院, 贵阳, 贵州 550025, 中国
}


摘要：随着我国经济快速发展，区域技术创新逐渐成为我国科技创新的主要动力。为提高区 域技术创新投入产出效率，本文收集了 2015 年 21 个地级市的数据，建立基于 DEA 模型的区 域 R\&D 投入产出效率评价体系, 对影响区域技术创新效率进行测度。因此建议政府应适当提 高贷款风险补偿资金的额度，从而进一步促进区域技术创新和经济发展。

关键词：贷款风险补偿资金 ; 区域技术创新 ; 区域技术创新效率 ; DEA 模型

\section{1. 引言}

科技进步是经济增长的主要动 力，区域技术创新逐渐成为我国保持 经济健康发展, 稳步提升经济实力的 重要保障。贷款风险补偿资金池作为 解决区域企业融资难问题的主要解决 措施，对区域技术创新有一定的影 响, 本文建立基于 DEA 模型的区域 R\&D 投入产出效率评价体系, 研究贷款风 险补偿资金对区域技术创新效率的影 响。Farre11 利用非预设生产函数来评 估效率，从而代替原先的预设生产函 数, 利用线性规划求出生产前沿, 并 提出以生产前沿衡量效率的方法, 从 而首次建立 DEA 基本模型。Charnes Cooper 和 Rhodes (1978) ${ }^{[1]}$ 在此基础 上, 建立了第一个完整模型 CCR 模 型, 他们将多投入多产出的效率衡量 转换为数学比例, 以线性规划求解有 效生产前沿，计算决策单元在固定规 模下的相对效率。1984 年 Banker, Charnes 和 Cooper ${ }^{[2]}$ 提出了 BCC 模型, $\mathrm{BCC}$ 模型允许变动规模报酬, 从而可以 得出规模效率和技术效率的线性规划 式, 最后可以得出各决策单元的技术 效率、规模效率情况。肖志杰 (1991) ${ }^{[3]}$ 在《估计技术进步滞后及超 前年限的要素增长型 DEA 模型》中提 出基于 DEA 思想的有限方案多目标决 策分析方法。

王艳芳, 邹开其 (2010) ${ }^{[4]}$ 将现代 风险测度方法中的单项投资风险评价 方法、项目组合投资风险评价方法和
投资方案风险比选评价方法应用到高 新技术风险投资中，分析了各高新投 资项目的合理性，这将在风险投资决策 分析中获得更高的实用价值。为贷款 风险补偿资金的使用已提供了有力支 撑。综上所述, 本文结合上述研究, 基于 DEA 模型的贷款风险补偿资金对 区域技术创新效率进行影响研究。

\section{2. 三阶段 DEA 模型构建}

\section{1 第一阶段 (DEA 模型)}

本阶段选取相关的投入产出数 据, 采用规模报酬可变的 DEA 即 BCC 模型进行分析, 分别得到各个决策单 元的技术效率值、纯技术效率值和规 模效率值, 对这些效率值进行初步测 度。

\section{2 第二阶段（SFA 方法）}

采用第一阶段的 DEA 模型对效率 值进行测度, 没有将外部宏观环境因 素、管理因素和随机干扰这三个因素 区分开, 直接测度相对效率值, 这样 使得测度结果不是针对管理效率的测 度。

Battese (1995) 为此把 $K$ 个环境 变量 $Z_{\mathrm{k}}=\left(Z_{1 \mathrm{k}}, Z_{2 \mathrm{k}}, \ldots, Z_{\mathrm{pk}}\right)$ 作为自 变量, 以投入的松弛量作为因变量, 对每一项投入的松弛量都建立一个 SFA 模型, 根据 Battese (1995) 松弛变量与 环境变量分析模型, 其中第 $\mathrm{n}$ 个回归 方程形式为: 
$s_{n k}=\beta^{n} z_{k}+v_{n k}+\mathrm{u}_{n k}, k=1,2, \ldots, k$

其中, $\mathrm{S}_{\mathrm{nk}}$ 表示第 $\mathrm{k}$ 个决策单元在第 $\mathrm{n}$ 种投入上的投入松驰变量; $v_{n k}+u_{n k}$ 为综 合干扰项， $\mathrm{V}_{\mathrm{nk}}$ 表示随机干扰且假定服 从正态分布, $v_{n k} \sim N\left(0, \sigma_{v_{n}}^{2}\right) ; \mathrm{u}_{\mathrm{nk}}$ 表 示管理因素且假定服从截断正态分 布, 即 $u_{n k} \sim N^{+}\left(u^{n}, \sigma_{v_{n}}^{2}\right) ; \beta^{n}$ 表示 选取的环境变量的待估参数 $\beta{ }^{\mathrm{n}} Z_{\mathrm{k}}$ 为环 境变量对投入松他变量 $\mathrm{S}_{\mathrm{nk}}$ 的影响。

\section{3 第三阶段（DEA 模型）}

利用第一阶段调整后的投入量 $x_{n k}^{*}$ 和原始的产出量, 再次利用 DEA 模型 估计各个决策单元的各个效率值。本 文采用三阶段 DEA 模型测算出来的效 率值才是剔除了环境变量和随机干扰 真正反映各区域研发投入产出的管理 效率。

\section{3. 变量选取与指标体系建立}

\section{1 变量选取与说明}

用三阶段 DEA 模型计算 R\&D 投入 产出效率的关键就是选择投入产出指 标, 本文在综合考虑了前两章的既得 数据和 DEA 方法对数据要求的基础上 选取了 21 个城市 2015 年度的五个投 入产出指标对国家研发投入产出效率 进行测算。研发投入只包含财力资本 和人力资本。产出指标包括专利申请 数、专利授予数、高新技术产业产 值。环境变量的选取包括经济、教 育、社会等外部影响因素。下面本文 将对这些外部因素进行说明。

由于本文研究的是贷款风险补偿 资金对区域 R\&D 投入产出效率，采用 拥有贷款风险补偿资金池的城市作为 研究样本, 并且有一大部分城市 2014 年之前关于贷款风险补偿资金数额的
数据缺失, 所以本文根据研究的需 要, 尽可能的扩大样本量, 最终选取 21 个城市 2015 年的数据作为样本。

\section{2 评价指标体系的建立}

在参考文献的基础上，本文将 R\&D 经费投入, $R \& D$ 人员全时当量为投入指 标; 同时把国内专利申请量、国内专 利授权量, 以及高新技术产业产值作 为产出指标, 把经济发展水平、教育 指标、固定资产投资、贷款风险补偿 资金、外贸依存度、市场化指数作为 宏观环境变量, 建立区域 R\&D 投入产 出的效率评价体系。如下表所示:

表 1 研发投入产出效率评价体系

\begin{tabular}{|c|c|c|}
\hline \multirow{2}{*}{ 投入 } & K & $\begin{array}{l}\text { 研究与试验发展 R\&D 经费支出 } \\
\text { (亿) }\end{array}$ \\
\hline & $\mathrm{L}$ & R\&D 人员折合全时当量(人年) \\
\hline \multirow{3}{*}{$\begin{array}{l}\text { 产出 } \\
\text { 变量 }\end{array}$} & $\mathrm{Y}_{1}$ & 国内专利申请量（件） \\
\hline & $\mathrm{Y}_{2}$ & 国内专利授权量（件） \\
\hline & $\mathrm{Y}_{3}$ & 高新技术产业产值(亿元) \\
\hline \multirow{6}{*}{$\begin{array}{l}\text { 宏观 } \\
\text { 环境 } \\
\text { 变量 }\end{array}$} & $\mathrm{X}_{2}$ & 经济发展水平 \\
\hline & $\mathrm{X}_{3}$ & 教育指标 \\
\hline & $\mathrm{X}_{4}$ & 固定资产投资 \\
\hline & $\mathrm{S}_{1}$ & 贷款风险补偿资金（万元） \\
\hline & $\mathrm{S}_{2}$ & 外贸依存度 \\
\hline & $\mathrm{S}_{3}$ & 市场化指数 \\
\hline
\end{tabular}

\section{4. 实证结果分析}

\section{1 第一阶段（DEA 模型）}

运用 DEA 模型对 2015 年的投入产 出效率值进行测度, 本文所用软件为 DEAP2. 1, 得到 2015 年第一阶段 DEA 模型测度结果。可知 2015 年本文所选 取样本城市的研发投入产出效率的平 均值为 0.499 , 说明了样本城市整体的 研发效率还有待提高; 纯技术效率的 均值为 0.661 , 说明 2015 年样本城市 整体研发资源的使用效率偏低; 样本 城市整体的规模效率均值为 0.782 , 说 
明 2015 年样本城市整体的研发资源投 入产出比例不相适应。具体来看，在 样本选取的城市中, 有三个城市处于 有效前沿面, 分别是嘉兴、佛山、惠 州; 技术效率有效的有 8 个城市; 规模 效率有效的城市有 3 个, 分别是嘉 兴、佛山、惠州。有 10 个城市的规模 报酬递增, 9 个城市的规模报酬递减, 有 3 个城市的规模报酬不变。

\section{2 第二阶段（SFA 方法）}

表 2 DEA 模型测度结果

\begin{tabular}{|c|c|c|c|c|}
\hline firm & crste & vrste & scale & \\
\hline 厦门 & 0.296 & 0.312 & 0.947 & irs \\
\hline 烟台 & 0.171 & 0.203 & 0.845 & irs \\
\hline 盐城 & 0.609 & 0.621 & 0.980 & irs \\
\hline 扬州 & 0.549 & 0.563 & 0.976 & irs \\
\hline 镇江 & 0.487 & 0.497 & 0.980 & irs \\
\hline 无锡 & 0.412 & 0.655 & 0.628 & drs \\
\hline 常州 & 0.450 & 0.576 & 0.781 & drs \\
\hline 嘉兴 & 1.000 & 1.000 & 1.000 & - \\
\hline 佛山 & 1.000 & 1.000 & 1.000 & - \\
\hline 宿迁 & 0.467 & 0.587 & 0.796 & irs \\
\hline 济南 & 0.354 & 0.365 & 0.968 & $\mathrm{drs}$ \\
\hline 青岛 & 0.398 & 0.531 & 0.750 & $\mathrm{drs}$ \\
\hline 苏州 & 0.561 & 1.000 & 0.561 & drs \\
\hline 泉州 & 0.676 & 1.000 & 0.676 & drs \\
\hline 莆田 & 0.326 & 0.614 & 0.532 & irs \\
\hline 开封 & 0.317 & 1.000 & 0.317 & irs \\
\hline 惠州 & 1.000 & 1.000 & 1.000 & - \\
\hline 洛阳 & 0.282 & 0.358 & 0.786 & irs \\
\hline 三明 & 0.463 & 0.800 & 0.579 & irs \\
\hline 广州 & 0.465 & 0.952 & 0.489 & drs \\
\hline 武汉 & 0.201 & 0.241 & 0.834 & drs \\
\hline 均值 & 0.499 & 0.661 & 0.782 & \\
\hline
\end{tabular}

注:crste 为技术效率, vrste 为纯技术效率, scale 为规模效率; irs 为规模报酬递增, drs 规模 报酬递减, 一为规模报酬不变。
本文选取了两个投入松弛变量, 分别为: $R \& D$ 人员折合全时当量 (人 年), 规模以上工业企业 R\&D 经费内部 支出 (万元)。因此要对每一个松弛变 量都要建立一个 SFA 模型, 其中环境 变量为: 经济发展水平、教育指标、固 定资产投资、贷款风险补偿资金、外 贸依存度、市场化指数, 利用软件 Frontier4. 1 进行 SFA 回归, 回归结果 如下表所示。

表 $3 R \& D$ 人员折合全时当量与环境变量 SFA 模 型回归结果

\begin{tabular}{|l|l|l|}
\hline & 系数 & 标准误差 \\
\hline 常数项 & -50967.97 & 42831.133 \\
\hline $\begin{array}{l}\text { 贷款风险补偿资 } \\
\text { 金 (万元) }\end{array}$ & 0.29584102 & 0.4510587 \\
\hline 外贸依存度 & 17747.183 & 11300.689 \\
\hline 市场化指数 & 4778.9929 & 4820.9572 \\
\hline 经济发展水平 & -0.080248901 & 0.15512396 \\
\hline 教育指标 & 0.028810876 & 0.025371383 \\
\hline 固定资产投资 & 10.327321 & 3.399672 \\
\hline
\end{tabular}

表 4 规模以上工业企业 R\&D 经费内部支出与环 境变量 SFA 模型回归结果

\begin{tabular}{|c|c|c|}
\hline & 系数 & 标准误差 \\
\hline 常数项 & -1004652.2 & 1002744.9 \\
\hline $\begin{array}{c}\text { 贷款风险补偿资 } \\
\text { 金 (万元) }\end{array}$ & 24.709582 & 10.560001 \\
\hline 外贸依存度 & 323940.79 & 264567.1 \\
\hline 市场化指数 & 12481.48 & 112866.27 \\
\hline 经济发展水平 & 4.1123781 & 3.6316984 \\
\hline 教育指标 & -0.98364942 & 0.59398441 \\
\hline 固定资产投资 & 462.33758 & 79.591724 \\
\hline
\end{tabular}

通过表 3 和表 4 , 可以看出:

(1)贷款风险补偿资金在两个模型 中，以样本城市 2015 年设立的资金池 额度衡量的贷款风险补偿资金的系数 均为正值, 说明了区域贷款风险补偿 资金的高低与投入松弛变量之间呈正 
向关系，即贷款风险补偿资金的提高 可以导致研发投入量的增加，降低研 发投入产出效率。并且, 通过比较两 个模型可以发现，贷款风险补偿资金 在第二个模型中的系数较大，对 “规 模以上工业企业 R\&D 经费内部支出” 的影响较大。

(2) 市场化指数。由于市场化指数 标准不一, 大多数研究以㚞纲, 王小 鲁，朱恒鹏（2015） ${ }^{[6]}$ 编写的《中国市 场化指数》中提供的市场化指数为研 究变量, 由于书中只有各省的市场化 指数, 所以本文选择样本市所在的省 的市场化指数进行替代。在两个模型 中, 市场化指数的系数均为正值, 说 明了市场化指数的高低与投入松弛变 量之间呈正向关系，即市场化指数的 提高可以导致研发投入量的增加，降 低研发投入产出效率。

\section{3 第三阶段（DEA 模型）}

在一阶段效率评价中包含这些环 境变量可能会对各个决策单元的效率 评价造成影响, 即处于较好环境的决 策单元的效率值会较高, 而处于不利 环境的决策单元的效率值会偏低, 因 此, 基于本文在二阶段中介绍的方法 对一阶段原来的投入量进行调整，使 得各个决策单元处于相同的外部环境 和运气下。本文利用软件 DEAP2. 1 对 调整后的投入产出量进行 DEA 测度, 结果如下表所示。
表 5 调整后 DEA 模型测度结果

\begin{tabular}{|c|c|c|c|c|}
\hline firm & crste & vrste & scale & \\
\hline 厦门 & 0.568 & 0.572 & 0.992 & irs \\
\hline 烟台 & 0.195 & 0.239 & 0.816 & irs \\
\hline 盐城 & 0.619 & 0.63 & 0.983 & irs \\
\hline 扬州 & 0.717 & 0.746 & 0.961 & irs \\
\hline 镇江 & 0.924 & 0.964 & 0.958 & irs \\
\hline 无锡 & 0.819 & 0.885 & 0.926 & drs \\
\hline 常州 & 0.89 & 0.89 & 0.999 & irs \\
\hline 嘉兴 & 1.000 & 1.000 & 1.000 & - \\
\hline 佛山 & 1. 000 & 1. 000 & 1.000 & - \\
\hline 宿迁 & 1. 000 & 1. 000 & 1.000 & - \\
\hline 济南 & 0.742 & 0.764 & 0.971 & $\mathrm{drs}$ \\
\hline 青岛 & 0.547 & 0.566 & 0.965 & drs \\
\hline 苏州 & 0.975 & 1.000 & 0.975 & $\mathrm{drs}$ \\
\hline 泉州 & 0.991 & 0.996 & 0.995 & irs \\
\hline 莆田 & 0.472 & 0.97 & 0.486 & irs \\
\hline 开封 & 0.638 & 1.000 & 0.638 & irs \\
\hline 惠州 & 0.883 & 0.94 & 0.94 & drs \\
\hline 洛阳 & 0.336 & 0.434 & 0.773 & irs \\
\hline 三明 & 0.398 & 0.771 & 0.516 & irs \\
\hline 广州 & 0.748 & 0.939 & 0.796 & $\mathrm{drs}$ \\
\hline 武汉 & 0.378 & 0.39 & 0.971 & drs \\
\hline 均值 & 0.707 & 0.795 & 0.889 & \\
\hline
\end{tabular}

注: crste 为技术效率, vrste 为纯技术效率, scale 为规模效率; irs 为规模报酬递增, $\mathrm{drs}$ 为 规模报酬递减, 一为规模报酬不变。

2015 年，本文选取样本城市的技 术效率的平均值为 0.707 , 纯技术效率 平均值为 0.795 , 规模效率的平均值为 0.889 , 与调整前相比分别提高了 $41.68 \% ， 20.27 \% ， 13.68 \%$ 。调整前未 达到技术效率有效的城市在调整后均 
有显著的提高, 宿迁、济南、开封的 技术效率分别提高了 $114.13 \%$, 109. 6\%，101. 26\%。调整后处于生产前 沿面的城市分别为嘉兴、佛山、宿 迁。效率值的变化说明研发投入产出 效率受环境变量的影响较为显著, 调 整后的 DEA 测度结果更加客观地反映 了各城市的研发投入管理水平。

\section{5. 结束语}

本文对贷款风险补偿资金的运行 机理进行深入研究, 并根据相关文献 分析了区域技术创新效率的影响因 素, 比较了各地区的技术创新效率。 由于现阶段对贷款风险补偿资金与区 域技术创新投入之间影响关系的研究 较少, 为研究贷款风险补偿资金对区 域技术创新投入的影响情况, 本文收 集了 2015 年 21 个地级市的非平衡面 板数据, 运用 DEAP, Frontier 等统计 软件, 构建 DEA 模型, 得到各地区技 术创新效率, 在此基础上引入多种宏 观环境影响因素, 对结果进行修正后 得到新的 DEA 模型。结果发现: 利用 贷款风险补偿资金等多种宏观影响因 素进行调整, 调整后处于生产前沿面 的城市分别为嘉兴、佛山、宿迁; 贷 款风险补偿资金对区域技术创新效率 有显著正向影响, 且对 “规模以上工 业企业 R\&D 经费内部支出” 的影响较 大。因此，政府应适当增加贷款风险 补偿资金的额度，从而促进区域技术 创新的投入, 为区域经济发展提供动 力。

\section{致谢}

基金项目: 本文获得 2017 年度贵 州财经大学校级科研项目（青年项 目）“贵州大数据产业集聚效应及金 融支持体系研究” 资助; 贵州财经大 学 2016 年度在校学生资助项目 “贷款
风险补偿资金对科技型中小企业技术 创新的影响机理研究”。

\section{参考文献}

[1] Charnes A, Cooper W W, Rhodes E. Measuring the efficiency of decision making units $\hat{\imath}[\mathrm{J}]$. European Journal of Operational Research, 1978, 2(6):429-444.

[2] Banker R D, Charnes A, Cooper W $\mathrm{W}$. Some models for the estimation of technical and scale inefficiencies in data envelopment analysis[J]. Management Science, 1984:10781092.

[3] 魏权龄, 李其荣, 肖志杰. 估计技 术进步滞后及超前年限的要素增长 型 DEA 模型 $[\mathrm{J}]$. 数量经济技术经 济研究，1991 (3) : 28-34.

[4] 王艳芳. 现代风险测度方法在高新 技术投资中的应用 $[\mathrm{A}]$. 中国灾害 防御协会风险分析专业委员会.

“中国视角的风险分析和危机反 应” - - 中国灾害防御协会风险分 析专业委员会第四届年会论文集 [C]. 中国灾害防御协会风险分析专 业委员会, 2010:7.

[5] Jondrow J, Lovell C A K, Materov I $\mathrm{S}$, et al. On the estimation of technical inefficiency in the stochastic frontier production function model $[\mathrm{J}]$. Journal of Econometrics, 1982, 19(2 - 3):233238.

[6]森纲, 王小鲁, 朱恒鹏. 中国市场化 指数: 各地区市场化相对进程 2011 年报告 [M]. 经济科学出版社, 2015 . 